\title{
Comparative evaluation of IUCD insertion in postpartum period with interval period in a tertiary health care center of north India
}

\author{
Alpana Agrawal ${ }^{1, *}$, Amita Sharma ${ }^{2}$, Neelima Agarwal $^{3}$, Manisha Gupta ${ }^{4}$ \\ ${ }^{1-4}$ Professor, ${ }^{1-4}$ Dept. of Obstetrics \& Gynaecology, Santosh Medical College and Hospital, Ghaziabad, Uttar Pradesh, India \\ *Corresponding Author: \\ Email: alpanaishi@gmail.com
}

\begin{abstract}
Introduction: Postpartum IUD insertion provides long term and effective contraception but there are concerns regarding increase in the risk of expulsion or perforation among researchers and clinicians. This study compares PPIUCD versus interval IUCD.

Materials and Methods: In study 125 postpartum (post placental and intra-caesarean) and 140 interval IUCD insertions (total 265 IUCD) were done. 245 cases completed the study 21 were lost to follow-up. Cu T 375 was used in the study. Exclusion criteria were -women with active PID, uterine anomaly, current carcinoma, chorioamnionitis or puerperal sepsis, prolonged rupture of membranes $>18 \mathrm{hrs}$, genital trauma, PPH history of ectopic pregnancy, any hemorrhagic disorder, genital infection, diabetes mellitus, heart disease, pelvic tuberculosis and woman or husband having multiple sexual partners. All were followed up for 6 months. Various socio-demographic factors and complications like expulsion, bleeding, pain, infection and medical removal were compared among groups.

Results: Most women came for follow up in both the groups (PPIUCD-75.8\% and Interval-71.2\%). The expulsion rate in PPIUCD group $(9.2 \%)$ was significantly higher than interval group $(2.4 \%)$ ( $\mathrm{p}<0.02) .11 .6 \%$ cases of PPIUCD group and $3.2 \%$ cases of Interval group reported with missing strings. The results were statistically significant $(p<0.01)$. No case of perforation was reported in either group. Satisfaction with IUCD was $75 \%$ in PPIUCD group and $80 \%$ in Interval. Removal rate of IUCD was almost similar in both the groups $(\mathrm{p}=0.39)$.

Conclusion: There is an increased risk of expulsion in PPIUCD insertion but its benefits outweigh the risks. So this method should be popularised across the country as a very effective method of interval contraception.
\end{abstract}

Keywords: Postpartum intrauterine contraceptive device complications, Satisfaction, Removal rate.

\section{Introduction}

Wider use of IUCD has the potential to reduce the overall number of unintended pregnancies more than any other method. However its acceptance rate is low. Although the Indian government offers IUCD services free of cost, it still remains largely underutilized. According to NFHS-3, IUCD account for only 1.2-1.6 $\%$ of the total contraceptive usage in the country. ${ }^{1}$

In the last decade, more and more women have chosen to give birth in health institutions. This preference has emerged due to the government's flagship program-Janani Suraksha Yojana, a conditional cash transfer scheme for promoting institutional deliveries $^{2}$ It is a part of government's efforts to reduce maternal and neonatal mortality under the National Health Mission. Postpartum period is one of the sensitive times of woman's life when she is in contact with health care facility and when both mother and new born need a special care. In India 65 per cent of women in the first year post-partum have an unmet need for family planning, out of which only $26 \%$ of woman are using any method of contraception. ${ }^{1}$ Postpartum contraceptive options are limited, barrier contraceptives and progesterone only pills. Both are user and compliance dependent methods and therefore have high failure rates. Traditionally Cut insertion was limited to interval period. But now recent studies on postpartum contraceptive methods have suggested the use of $\mathrm{Cu} \mathrm{T}$ in postpartum period which can provide long term and effective contraception with failure rate of $<1 \% 3^{3}$ Immediate postpartum IUCD service became a Government of India approved program in 2010. Under the new program being implemented by the Government of India in some states in collaboration with Jhpiego, pregnant women are counseled for the use of IUCDs during antenatal period itself and the IUCD is inserted soon after the woman delivers the baby, following proper consent. Delaying insertions until later is less effective because most clients tend not to return to facilities for FP services. ${ }^{4}$

Postpartum IUD insertion. However may increase the risk of adverse events affecting safety (e.g. perforation, pain, bleeding) as well as effectiveness (i.e. expulsion). Whether postpartum IUD insertion increases the risk of expulsion or perforation has been of particular concern to researchers and clinicians. In earlier studies differences in the expulsion rates were related to the time of insertion, type of IUD used, technique of insertion and skill \& experience of the service providers. Since then various advancements have been tried to decrease expulsion rates and improve PPIUCD acceptance.

According to a 2010 Cochrane review, PPIUCD is a safe and effective contraceptive method. ${ }^{5}$ New understanding of this postpartum contraception necessitates examination of advantages and disadvantages of PPIUCD from a new perspective. 
The aims and objectives of the study was to evaluate the safety and efficacy of insertion of immediate postpartum IUD using $\mathrm{Cu} 375$ in women delivering vaginally or by caesarean section and to compare it with interval insertion of IUD.

\section{Materials and Methods}

It was an interventional study conducted in the Department of Obstetrics and Gynaecology, Santosh Medical College and Hospital, Ghaziabad. Duration of study was two years from September 2015 to August 2017. Total 265 IUCD insertions were done. Out of this 125 cases were of postpartum (post placental and intracaesarean) and 140 were interval insertions. Five women of PPIUCD group and 15 of Interval group were lost to follow up. Further analysis was done on 245 cases that completed the study. Women desirous of $\mathrm{Cu} 375$ insertion willing to comply study protocol and women meeting all the eligibility criteria for Postpartum IUCD Insertion / Interval insertion, after taking informed consent were included in the study. The women with active pelvic inflammatory disease, uterine cavity anomaly, current carcinoma chorioamnionitis or puerperal sepsis, prolonged rupture of membranes of $>18 \mathrm{hrs}$, extensive genital trauma, unresolved PPH past history of ectopic pregnancy history of any hemorrhagic disorder history of past or current genital infection, diabetes mellitus, known history of heart disease woman or husband having multiple sexual partners and known pelvic tuberculosis were excluded from the study.

The women presenting to antenatal OPD and to labour room in early labour were counselled about family planning methods and encouraged to opt for PPIUCD. In the study group $\mathrm{Cu} 375$ was inserted within 10 minutes of expulsion of placenta in normal vaginal delivery using Kelly's placental forceps, taking all aseptic precautions as per the guidelines of USAID Ministry of health and family welfare, government of India 2010. ${ }^{6}$ Intra caesarean $\mathrm{Cu} 375$ was placed at fundus manually and IUD thread was left in lower uterine segment without trimming the thread. All postpartum women were observed for 6 hours after delivery and re-examined before discharge from the hospital.

In control group $\mathrm{Cu} 375$ was inserted between 4 th to 7th days of menstrual cycle by standard 'no touch' withdrawal technique, under all aseptic precautions. Physical and pelvic examinations were carried out to check the threads of $\mathrm{Cu} 375$ to check for signs of infection and excessive bleeding. The women were followed at 1 week 3 weeks, 6 weeks 3 months and 6 months.

Safety was assessed in terms of expulsion IUCD failure/pregnancy rate perforation removal of IUCD visibility of strings and various complains at each visit.

Various socio-demographic factors and complications were compared among groups. The comparison of complications like expulsion, bleeding, pain, infection and medical removal was done. The observations are described in terms of percentages. Both groups were compared with respect to clinical outcomes. Student T test was used to detect differences in prevalence rate of clinical outcomes, and $\mathrm{P}<0.05$ was considered statistically significant. Data were analysed using SPSS statistical software version 21.0.

\section{Results and Discussion}

Total 265 IUCD insertions were done. Out of this, 125 cases were of postpartum (post placental and intracaesarean) and 140 were interval insertions. Five women of PPIUCD group and 15 of Interval group were lost to follow up. Further analysis was done on 245 cases that completed the study.

Majority of the cases who accepted PPIUCD belonged to the age group up to 25 years $(56.7 \%)$ and those in Interval (control group) belonged to 26-30 years $(41.6 \%)$ (Table 1$)$.

Majority of the patients in study belonged to lower middle class: PPIUCD (66.7\%) and Interval (48.8\%) according to the modified Kuppuswami classification. ${ }^{7}$ (Table 2)

In both the groups, IUCD insertions were done more in multiparous women. In the present study $64.2 \%$ women in PPIUCD group and $58.4 \%$ in Interval group were multiparous. (Table 3 )

Out of 265 women recruited, 245 women came for follow up. Most women came for follow up upto six weeks in PPIUCD group (41.6\%). Women from Interval group mostly got followed up at and beyond six months $(44 \%)$. Most women came to OPD clinics for follow up in both the study groups (PPIUCD-75.8\% and Interval $71.2 \%$ ). In the present study only $7.5 \%$ of women were lost to follow up which is low (Table 4).

In another study done in District Hospital of Bolangir, Odisha, Mishra et al. reported 23\% women being lost to follow-up. ${ }^{8}$ Similarly a lost to follow-up of $21.4 \%$ was reported by Shukla et al. in their study done in a Medical college in Uttar Pradesh. ${ }^{9}$

In the present study $53.3 \%$ women in PPIUCD group and $54.4 \%$ women in Interval group had no complaints (Table 5).

There were 11 expulsions in PPIUCD group $(9.2 \%)$ and 3 in Interval group $(2.4 \%)$. The expulsion rate in PPIUCD group is significantly high $(\mathrm{p}<0.02)$ (Table 5). This could be due to improper technique of PPIUCD insertion. In a study by Shukla et al. ${ }^{9}$ the cumulative expulsion rate at the end of 6 months was $10.68 \%$. According to study by Gupta et al. ${ }^{10}$ rate of expulsion was $4.33 \%$ in PPIUCD group \& $2 \%$ in Interval IUCD group (statistically insignificant $\mathrm{p}<0.05$ ).

Infection rate was $10 \%$ in PPIUCD group and $15.2 \%$ in Interval group. The results were statistically insignificant $(\mathrm{p}=0.22)$ (Table 5). 
Pain was reported in $4.1 \%$ of cases in PPIUCD group and $3.2 \%$ of cases in Interval group. The results were statistically insignificant $(\mathrm{p}=0.68)$.

In the present study 14 cases of PPIUCD group $(11.6 \%)$ and 4 cases of Interval group (3.2\%) were reported with missing strings. The results were statistically significant $(\mathrm{p}<0.01)$ (Table 5). Missing strings were checked for with the help of ultrasonography and if IUCD was found in situ, patient were counselled to continue with the usage of it. The incidence was higher in PPIUCD group which was probably due to coiling of long threads of IUCD inside the uterine cavity.

Most common complaint observed in Interval group was heavy menstrual bleeding (8\%). 5\% women in PPIUCD group had similar complaint. The results were statistically insignificant $(\mathrm{p}=0.34)$ (Table 5).

The risk of complications like bleeding, pain in lower abdomen and infection were relatively less in both the groups in our study.

Complaint of long thread was found in PPIUCD group (7 cases) which was cut at clinic visits for followup by the patients. No such complaint was found in Interval group (Table 5).

Only single case of failure in the form of pregnancy occurred in the Interval group. No case of perforation was reported in either group, similar to studies done by Singh U et al. ${ }^{3}$ and Gupta et al. ${ }^{10}$ This decreased risk of uterine perforation may be because of thick wall of the uterus.
$75 \%$ women in PPIUCD group and $80 \%$ in Interval group were satisfied with IUCD. So satisfaction rate was quite good in both groups (Fig. 1). This emphasizes that mode of insertion is not affecting the satisfaction level of women. Thus it may be presumed that continuation of IUCD depends more on the proper technique and regular and timely follow up with the prompt identification of problem and management. According to study by Gupta et al. satisfaction rates were $90 \%$ (PPIUCD group) \& 92\% (Interval group). ${ }^{10}$ In study by Singh $\mathrm{U}$ et al. satisfaction rates were $87.6 \%$ and $81.81 \%$ for PPIUCD and Interval groups respectively. $^{3}$

Twenty cases in PPIUCD group (16.6\%) and 16 cases in Interval group (12.8\%) got IUCD removed (Fig. 2). The comparison between groups were statistically insignificant $(\mathrm{p}=0.39)$. In study by Gupta et al. ${ }^{10}$ removal rate was $5.66 \%$ in PPIUCD group \& $6 \%$ in Interval group. In study by Singh $\mathrm{U}$ et al. ${ }^{3}$ rate was $4 \%$ in PPIUCD group and $6 \%$ in Interval group. Most common cause of removal of IUCD among women using PPIUCD was bleeding (35\%) and among those using Interval IUCD was desired conception $(31.25 \%)$ (Table 6) According to study by Soni $\mathrm{M}$ et al. ${ }^{11}$ bleeding and pain were most common causes of removal of PPIUCD. In a study by Gupta et al. ${ }^{10}$ number of removal of IUCD was almost similar in both groups $(5.6 \% \mathrm{v} / \mathrm{s} 6.0 \%)$ but bleeding as a cause of removal was significantly more in interval group $(23.5 \% \mathrm{v} / \mathrm{s} 88.5 \%)$.

Table 1: Age-wise acceptance of IUCD

\begin{tabular}{|l|c|c|c|c|}
\hline Age(in years) & PPIUCD $(\mathbf{n = 1 2 0})$ & PPIUCD $(\boldsymbol{\%})$ & Interval(n=125) & Interval $(\%)$ \\
\hline Upto 25 & 68 & 56.7 & 35 & 28 \\
\hline $26-30$ & 40 & 33.3 & 52 & 41.6 \\
\hline $31-35$ & 11 & 9.2 & 26 & 20.8 \\
\hline $36-40$ & 1 & 0.8 & 9 & 7.2 \\
\hline $41 \&$ above & 0 & 0 & 3 & 2.4 \\
\hline
\end{tabular}

Table 2: Distribution of women according to socio-economic status

\begin{tabular}{|l|c|c|c|c|}
\hline Socio-Economic status & PPIUCD(n=120) & PPIUCD $(\%)$ & Interval $(\mathbf{\%}=125)$ & Interval (\%) \\
\hline lower & 4 & 3.3 & 7 & 5.6 \\
\hline upper lower & 31 & 25.8 & 6 & 4.8 \\
\hline lower middle & 80 & 66.7 & 61 & 48.8 \\
\hline upper middle & 5 & 4.2 & 9 & 7.2 \\
\hline
\end{tabular}

Table 3: Distribution of women according to parity

\begin{tabular}{|l|c|c|c|c|}
\hline \multicolumn{1}{|c|}{ Parity } & PPIUCD $(\mathbf{n = 1 2 0})$ & PPIUCD $(\%)$ & Interval $(\mathbf{n = 1 2 5})$ & Interval (\%) \\
\hline P1 & 43 & 35.8 & 30 & 24 \\
\hline P2-P4 & 77 & 64.2 & 73 & 58.4 \\
\hline >P4 & 0 & 0 & 22 & 17.6 \\
\hline
\end{tabular}

Table 4: Follow up after IUCD insertion

\begin{tabular}{|l|c|c|c|c|}
\hline Follow up & PPIUCD $(\mathbf{n = 1 2 0})$ & PPIUCD $(\boldsymbol{\%})$ & Interval $(\mathbf{n = 1 2 5})$ & Interval (\%) \\
\hline upto 6 weeks & 50 & 41.6 & 41 & 32.8 \\
\hline 6 weeks or more & 21 & 17.5 & 12 & 9.6 \\
\hline 3 months & 12 & 10 & 22 & 17.6 \\
\hline 6 months or more & 45 & 37.5 & 55 & 44 \\
\hline
\end{tabular}


Table 5: Findings at follow up

\begin{tabular}{|l|c|c|c|c|c|c|}
\hline S. No. & Findings at follow up & \multicolumn{2}{|c|}{ PPIUCD } & \multicolumn{2}{|c|}{ Interval } & \multirow{2}{*}{ P value (fisher exact test) } \\
\cline { 3 - 6 } & & $\mathbf{N = 1 2 0}$ & $\mathbf{\%}$ & $\mathbf{N = 1 2 5}$ & $\mathbf{\%}$ & \\
\hline 1 & Expulsion & 11 & 9.2 & 3 & 2.4 & 0.02 \\
\hline 2 & Infection & 12 & 10 & 19 & 15.2 & 0.22 \\
\hline 3 & Missing Strings & 14 & 11.6 & 4 & 3.2 & 0.01 \\
\hline 4 & $\begin{array}{c}\text { Heavy Menstrual } \\
\text { Bleeding }\end{array}$ & 6 & 5 & 10 & 8 & 0.34 \\
\hline 5 & Pain & 5 & 4.1 & 4 & 3.2 & 0.68 \\
\hline 6 & No Complaint & 64 & 53.3 & 68 & 54.4 & 0.86 \\
\hline 7 & Long Thread & 7 & 5.8 & 0 & 0 & - \\
\hline 8 & Failure & 0 & 0 & 1 & 0.8 & - \\
\hline
\end{tabular}

Table 6: Causes of removal of IUCDs

\begin{tabular}{|l|c|c|c|c|}
\hline Causes of Removal & PPIUCD(n=120) & PPIUCD (\%) & Interval (n=125) & Interval (\%) \\
\hline Social Causes & 1 & 5 & 2 & 12.5 \\
\hline Bleeding & 7 & 35 & 2 & 12.5 \\
\hline Missing Strings & 3 & 15 & 1 & 6.5 \\
\hline Discharge P/V & 4 & 20 & 2 & 12.5 \\
\hline Pain & 3 & 15 & 2 & 12.5. \\
\hline For Conception & 1 & 5 & 5 & 31.25 \\
\hline Other Causes & 1 & 5 & 2 & 12.5 \\
\hline
\end{tabular}

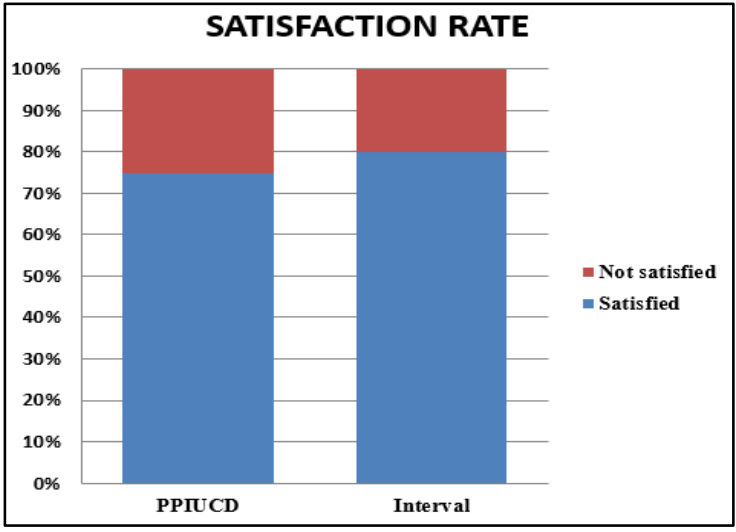

Fig. 1: Satisfaction rate with IUCD

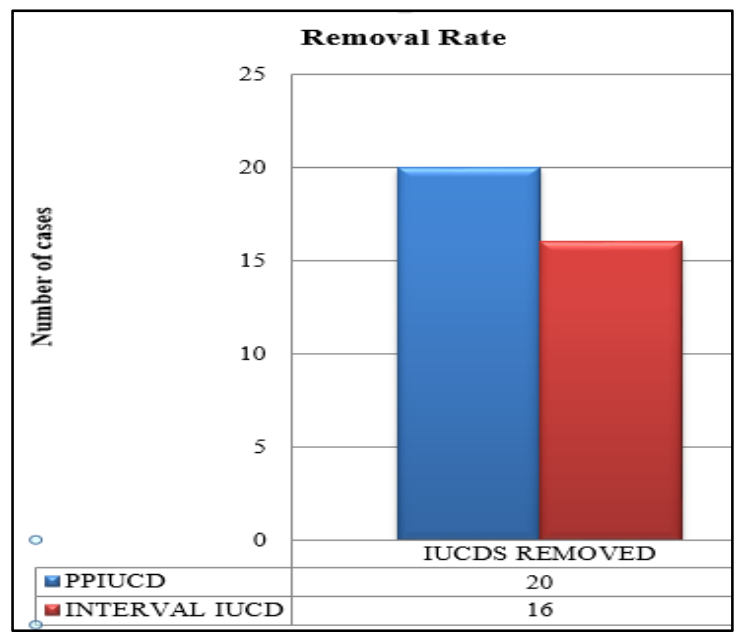

\section{Conclusion}

As there is an increased risk of expulsion in PPIUCD insertion, so questions are raised regarding its efficacy. But, its benefits outweigh the risks. So this method should be popularised across the country as an option to all women undergoing institutional deliveries in tertiary health centres irrespective of the mode of delivery.

\section{References}

1. International Institute for Population Sciences (IIPS) and Macro International. 2007. National Family Health Survey (NFHS-3) India. 2005-2006;1.

2. National Health Portal [Internet]. New Delhi: Ministry of Health and Family Welfare; 2014 [Janani Suraksha Yojana]. Available from: http://www.nhp.gov.in/jsy (accessed 12 June 2018)].

3. Singh U, Sonkar S, Yadav P, Dayal M, Gupta V, Saxena S. et al. Comparative evaluation of postpartum IUCD versus interval IUCD at a tertiary care centre in Allahabad. Int J Reprod Contracept Obstet Gynecol. 2017;6:1534-38

4. Saroj Pachauri. Priority strategies for India's family planning programme: A review. Ind J Med Res. 2014;140:137-46.

5. Grimes DA, Lopez LM, Schulz KF, et al. Immediate post-partum insertion of intrauterine devices. Cochrane Database of Syst Rev. 2010. Art. No.: CD003036. doi:10.1002/14651858.CD003036.pub 2.

6. Family Planning Division, Ministry of Health and Family Welfare (IN). Postpartum IUCD reference manual. New Delhi: Government of India. 2010.[updated 2010 Nov; cited 2013 April 15]

Fig. 2: Removal rate of IUCD 
7. Kuppuswamy's Socio-Economic Status Scale: A Revision of Occupation and Income Criteria for 2016.

Available from:

https://www.researchgate.net/publication/307627556_Ku ppuswamy's_Socio-

Economic_Status_Scale_A_Revision_of_Occupation_an d_Income_Criteria_for_2016.

8. Mishra S. Evaluation of safety, efficacy, and expulsion of post-placental and intra-cesarean insertion of intrauterine contraceptive devices (PPIUCD). J Obstet Gynaecol India. 2014;64:337-43.
9. Shukla M, Qureshi S, Chandravati. Post-plecental intrauterine device insertion - A five year experience at a tertiary care centre in north India. Indian J Med Res. 2012;136:432-35.

10. Gupta A, Verma A, Chauhan J. Evaluation of PPIUCD versus interval IUCD (380A) insertion in a teaching hospital of Western U. P. Int J Reprod Contracept Obstet Gynecol. 2013;2(2):204-208.

11. Soni M, Sharma V, Bhat MP, Sharma A. Post-placental postpartum intrauterine contraceptive devices insertion: our scenario. Int J Reprod Contracept Obstet Gynecol. 2016;5:766-69. 